\title{
DIET INFLUENCES THE ACCUMULATION OF SHORT-CHAIN FATTY ACIDS ASSOCIATED WITH THE GUT MICROBIOTA IN THE GRASS CARP (CTENOPHARYNGODON IDELLUS) HINDGUT
}

\author{
LI, Z. F. ${ }^{1,2}-$ XIE, J. ${ }^{1,2^{*}}-$ YU, E. M. ${ }^{1,2}-$ WANG, G. J. ${ }^{1,2}-$ ZHANG, X. K. ${ }^{3}-$ YU, D. G. ${ }^{1,2}-$ \\ ZHANG, K. ${ }^{1,2}-$ GONG, W. B. ${ }^{1,2}$
}

${ }^{1}$ Key Laboratory of Tropical and Subtropical Fishery Resource Application and Cultivation, Pearl River Fisheries Research Institute, Chinese Academy of Fishery Sciences, No.1, Xingyu Road, Liwan, Guangzhou, Guangdong 510380, China ${ }^{2}$ Guangdong Ecological Remediation of Aquaculture Pollution Research Center, Guangzhou,
Guangdong 510380, China

${ }^{3}$ Research Center of Aquatic Organism Conservation and Water Ecosystem Restoration in Anhui Province, Anqing Normal University, Anqing, Anhui 246011, China

*Corresponding author

e-mail: xiejunhy01@126.com; phone: +86-20-8161-6178

(Received $19^{\text {th }}$ Jun 2019; accepted $28^{\text {th }}$ Aug 2019)

\begin{abstract}
Diet changes the composition and function of the gut microbiota (GM). Short-chain fatty acids (SCFAs) are mainly produced through carbohydrate fermentation by the GM. It remains unclear whether changing the diet influences the accumulation of SCFAs in the grass carp (Ctenopharyngodon idellus) gut. To address this question, we compared SCFA accumulation with GM changes in the hindgut contents of grass carp in groups fed hybrid giant napier (Pennisetum sinese Roxb, HG), formula feed (FG), and broad bean (Vicia faba, BG). Our results showed that diet significantly influenced the SCFA concentrations in the hindgut of grass carp. By eliminating the influences of dietary SCFA, acetate and total SCFA accumulation in the hindgut of grass carp turned out to be positively associated with dietary cellulose contents. Most of the enriched bacterial biomarkers in the HG group that consumed the most dietary cellulose were SCFA-producing bacteria. These results implied that diet could regulate the relative abundances of potential SCFA-producing bacteria and SCFA accumulation in the grass carp hindgut. These findings shed light onto GM functions related to SCFA production and associative functions between SCFAs and the GM of grass carp.
\end{abstract}

Keywords: aquaculture, carbohydrate fermentation, cellulose, high-throughput sequencing, microbial metabolism

\section{Introduction}

In mammals, short-chain fatty acids (SCFAs) such as acetate, butyrate, and propionate are essential host energy sources (Stevens and Hume, 1998; Spiljar et al., 2017; Leblanc et al., 2017), which act as signal-transduction molecules via G proteincoupled receptors and as epigenetic regulators of gene expression by inhibiting histone deacetylase (Kasubuchi et al., 2015; Cohen et al., 2017). SCFAs are involved in regulating glucose and lipid metabolism, stimulating the proliferation and differentiation of intestinal enterocytes, and reducing the intestinal $\mathrm{pH}$ (thereby promoting the absorption of minerals by increasing their solubility) (Barczynska et al., 2016; Postler and Ghosh, 2017). SCFAs are also key regulators of virtually every aspect of the intestinal immune system, and they play key roles in the prevention and treatment of metabolic syndromes, bowel disorders, and cancer (Kasubuchi et al., 2015; Postler and Ghosh, 2017; Fukuda et al., 2012; Flint et al., 2015; Safari et al., 2016). Although 
comparatively less research has been conducted with fish than with mammals, high intestinal SCFA concentrations occur in some marine herbivorous fishes and SCFAs produced by the hindgut microbiota are used as a blood fuel for energy purposes or for lipid synthesis by the host fish (Clements et al., 1994; Clements and Choat, 1995, 1997; Seeto et al., 1996; Mountfort et al., 2002).

Naturally, SCFAs are mainly produced through carbohydrate fermentation by gut microbiota in the host's intestines (Flint et al., 2015; Clements and Choat, 1995; Mountfort et al., 2002; Hao et al., 2017b). However, with the collapse of wild fishery resources, aquaculture has become the main way to produce fish protein. In addition, formula feed has replaced natural food to become the primary, or even sole food for cultured fish.

Diet is believed to be the major factor that changes the composition and functions of fish gut microbiota (Ni et al., 2014a; Faith and Gordon, 2011; Claesson et al., 2012; Bolnick et al., 2015; Miyake et al., 2015; Hao et al., 2017a). In addition, the quantities and number of SCFA species are markedly influenced by carbohydrate substrates (Hao et al., 2017a; Mountfort et al., 1993; Kihara and Sakata, 1997, 2002). Kihara and Sakata (2002) reported that alpha starch is the best substrate for producing SCFAs in the tilapia (Oreochromis niloticus) gut by microbial fermentation. Mountfort et al. (1993) isolated a bacterium, Eubacterium sp. P-1 (DSM 6788), from the mullet gut contents, which anaerobically ferments pectin to produce $163 \mathrm{~mol}$ acetate, $30 \mathrm{~mol}$ ethanol, $88 \mathrm{~mol}$ methanol, and $48 \mathrm{~mol}$ formate per $100 \mathrm{~mol}$ pectin monomer, whereas it anaerobically ferments hexose in cellobiose or starch to produce $39 \mathrm{~mol}$ acetate, $128 \mathrm{~mol}$ ethanol, and 41 mol formate per $100 \mathrm{~mol}$ hexose. However, it remains unclear whether changing the diet from natural food to artificial feed reduces SCFA accumulation in the fish gut. Since acetate absorption is driven by an SCFA concentration gradient between the blood and intestines, and the rates of absorption increase with intestinal concentrations (Titus and Ahearn, 1991), the answer to the question will show which feed formula promotes SCFA accumulation in hindgut and enhances the growth and health of fish, considering there are many studies have shown that using SCFAs and their salts as feed supplements enhance fish production (Goosen et al., 2011; Ringø, 1992; Da et al., 2013).

Grass carp (Ctenopharyngodon idella) is one of the most important native Chinese freshwater herbivorous fish, representing the largest freshwater aquaculture product worldwide (Ni et al., 2014a; FAO, 2014; Wang et al., 2015). Recently, a high-density culture formulation of grass carp feed with broad bean (Vicia faba) or formula feed in ponds has started spreading in China. The changes of the gut microbiota in grass carp caused by diet were described previously (Ni et al., 2014a). However, given that broad bean and formula feeds contain high protein and low cellulose concentrations, it is unclear whether those changes alter SCFA accumulation in the hindgut of grass carp. Considering the usability of carbohydrate substrates in fermentation by the gut microbiota, the nutritional contents of feeds, and the co-evolution between the gut microbiota and host's feeding habits, we hypothesized that whereas feeding formula feeds would increase grass carp growth and SCFA fermentation in the hindgut, feeding natural grass would enrich the cellulose- degrading bacteria in the hindgut of grass carp. To test this hypothesis, we compared the compositions of gut microbiota with cellulose levels and SCFA accumulation in hindgut of grass carp fed hybrid giant napier (Pennisetum sinese Roxb), formula feed, and broad beans. 


\section{Materials and methods}

\section{Experimental design and sample collection}

The experiment was conducted in the precise aquaculture base of the Pearl River Fisheries Research Institute of China $\left(113^{\circ} 13^{\prime} 02^{\prime \prime}\right.$ E, $\left.23^{\circ} 04^{\prime} 07^{\prime \prime} \mathrm{N}\right)$ over a period of 60 days from May 23, 2015 to July 24, 2015. Grass carps weighing approximately $500 \mathrm{~g}$ individually from the same parents was collected from an artificial pond at Foshan Tongwei Fisheries Co. (Guangdong, China). The experiment was divided into three groups. Each group, including 30 individuals, was fed with hybrid giant napier $(\mathrm{H})$, formula feed $(\mathrm{F})$, or broad bean $(\mathrm{B})$, respectively. The daily feed amount was $3 \%$ of the total weight of grass carps in formula feed group and broad bean group, and $10 \%$ of the total weight of grass carps in hybrid giant napier group. The uneaten feed was removed after $1 \mathrm{~h}$ of feeding. Broad beans were marinated in fresh water $24 \mathrm{~h}$ before they were fed to grass carp. After 2 months of being fed hybrid giant napier, formula feed, or marinated broad bean at 09:00 and 16:00 each day in the artifificial pond, three carps in each diet group were collected and euthanized by submersion in $60 \mathrm{mg} / \mathrm{L}$ tricaine methane sulfonate solution.

After two months, the grass carp were dissected under sterile conditions to obtain their hindgut contents for total microbial DNA extraction and SCFA concentration measurements, according to a previously described method (Ni et al., 2014a; Li et al., 2018). The groups were named based on the feed type. For example, FG indicates that the microbiota was collected from the hindgut of grass carp fed with formula feed.

\section{Determination of nutritional contents in feeds}

The crude fiber contents, crude ash contents, crude protein contents, and crude fat contents in fresh hybrid giant napier, marinated broad beans, and formula feed were determined according to standard methods (ISO 6541:1981, ISO 5984:2002, ISO 5983:1979, and ISO 6492:1999).

\section{Determination of SCFA concentrations}

SCFAs (acetate, propionate, butyrate, iso-butyrate, valerate, and iso-valerate) in feeds and the hindgut contents of grass carp fed with different feeds were analyzed by gas chromatography using the method proposed by Schwiertz et al. (2012), with some modifications. Briefly, each sample of $300 \mathrm{mg}$ (wet weight) was weighed $\left(10^{-4} \mathrm{~g}\right.$

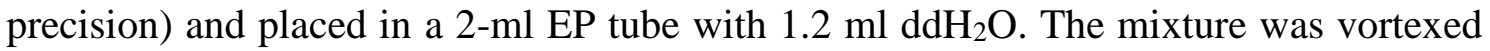
for $30 \mathrm{~s}$, homogenized in a ball mill for $4 \mathrm{~min}$ at $45 \mathrm{~Hz}$, and sonicated for $5 \mathrm{~min}$ in ice water. The mixture was centrifuged at $5,000 \mathrm{rpm}$ for $20 \mathrm{~min}$ at $4{ }^{\circ} \mathrm{C}$, and the supernatant $(0.6 \mathrm{ml})$ was collected for metabolite extraction. Next, $0.15 \mathrm{ml} \mathrm{H}_{2} \mathrm{SO}_{4}(50 \%)$ and $50 \mu \mathrm{g}$ $\mathrm{SCFA} / \mathrm{ml}$ ether were added to each supernatant, after which the supernatant was vortexed for $30 \mathrm{~s}$ and centrifuged $\left(10 \mathrm{~min}, 12000 \mathrm{rpm}, 4{ }^{\circ} \mathrm{C}\right)$. The supernatant was passed through a nylon filter $(0.45 \mu \mathrm{m})$ into a gas chromatography vial. SCFAs were analyzed using a GC2025 gas chromatograph (Shimazdu; Kyoto, Japan) with an automatic injector (AOC20i) at $240{ }^{\circ} \mathrm{C}$, using a flame-ionization detector (Shimadzu Deutschland $\mathrm{GmbH}$, Duisburg, Germany) at $240{ }^{\circ} \mathrm{C}$, equipped with an HP-Innowax capillary column (Agilent, Santa Clara, USA; $30 \mathrm{~m} \times 0.25 \mathrm{~mm}$ i.d. $\times 0.25 \mu \mathrm{m}$ f.d.). The injection volume was $1 \mu \mathrm{l}$, the carrier gas was helium (flow rate, $1 \mathrm{ml} / \mathrm{min}$ ), and the mode of injection was splitless. The oven temperature program was $50{ }^{\circ} \mathrm{C}$ for $3 \mathrm{~min}$, 
followed by an increase to $180{ }^{\circ} \mathrm{C}$ (held for $0 \mathrm{~min}$ ) at $8{ }^{\circ} \mathrm{C} / \mathrm{min}$, and a further increase to $200{ }^{\circ} \mathrm{C}$ (held for $5 \mathrm{~min}$ ) at $50^{\circ} \mathrm{C} / \mathrm{min}$. Other parameters used were: gas helium flow, $30 \mathrm{ml} / \mathrm{min}$; hydrogen flow, $40 \mathrm{ml} / \mathrm{min}$; and airflow, $400 \mathrm{ml} / \mathrm{min}$.

\section{DNA extraction and sequencing}

Total genomic DNA was extracted from the gut samples using a Gut Microbial DNA Extraction Kit (Omega, USA). DNA concentrations and purities were evaluated using $1 \%$ agarose gels. DNA samples were diluted to $1 \mathrm{ng} / \mu \mathrm{l}$ using sterile water before amplification was performed (Li et al., 2017).

The V4 region of the 16S rRNA gene was amplified using primers 515F and 806R, which contain sample-specific barcodes (Yan et al., 2016). PCR was performed in 30- $\mu 1$ reaction volumes with $15 \mu \mathrm{l}$ of the Phusion ${ }^{\circledR}$ High-Fidelity PCR Master Mix (New England BioLabs, USA), $0.2 \mu \mathrm{M}$ of the forward and reverse primers, and approximately $10 \mathrm{ng}$ of template DNA. The thermal cycling conditions used were as follows: initial denaturation at $98^{\circ} \mathrm{C}$ for $1 \mathrm{~min}$; followed by 30 cycles of denaturation at $98{ }^{\circ} \mathrm{C}$ for $10 \mathrm{~s}$, annealing at $50{ }^{\circ} \mathrm{C}$ for $30 \mathrm{~s}$, and elongation at $72{ }^{\circ} \mathrm{C}$ for $60 \mathrm{~s}$; and a final elongation step at $72{ }^{\circ} \mathrm{C}$ for $5 \mathrm{~min}$ (Li et al., 2018).

The PCR products were mixed with the same volume of $1 \times$ loading buffer (containing SYBR Green) and electrophoresed on 2\% agarose gels for detection. Samples between 400 and 450 bp in size were chosen for further experiments. The PCR products were mixed at an equidensity ratio; then, the mixed PCR products were purified using the GeneJET Gel Extraction Kit (Thermo Scientific, USA).

Sequencing libraries were constructed using the NEB Next ${ }^{\circledR}$ Ultra $^{\mathrm{TM}}$ DNA Library Prep Kit (NEB, USA), according to the manufacturer's recommendations, and index codes were added. The library quality was assessed using a Qubit ${ }^{@} 2.0$ Fluorometer $^{\circ}$ (Thermo Scientific, USA) and an Agilent Bioanalyzer 2100 system (Agilent Technologies, USA). Finally, the libraries were sequenced using the Illumina MiSeq platform, and 250-bp paired-end reads were generated.

\section{Sequence data analysis}

Paired-end reads from the original DNA fragments were merged using FLASH software. Paired-end reads were assigned to each sample based on the sample-specific barcodes. Sequences analysis was performed using the UPARSE software package with the UPARSE-OTU and UPARSE-OTUref algorithms (Edgar, 2013). QIIME 1.9.0 software (Caporaso et al., 2010) and the vegan package (Dixon, 2003) in the R platform (R Core Team, 2014) were used to analyze alpha (within samples) and beta (among samples) diversity. Sequences with $\geq 97 \%$ similarity were assigned to the same operational taxonomic units (OTUs). We selected representative sequences for each OTU and used the RDP classifier to annotate the taxonomic information for each representative sequence (Wang et al., 2007). To compute alpha diversities, we rarified the OTU table and calculated three metrics: Chao1 estimated species abundance, observed species estimated as the number of unique OTUs found in each sample, and the Shannon index. Rarefaction curves were generated based on these three metrics.

Correspondence analysis (CA), non-parametric multivariate analysis of variance (MANOVA) (Anderson, 2001), and non-parametric significance testing of differences were conducted using the vegan package in the $\mathrm{R}$ platform. A heatmap profile was drawn using HemI 1.0 (Deng et al., 2014). 
All sequencing data were deposited in the NCBI Sequence Read Archive (SRA) under accession number SRP080980. The SRA records can be accessed at http://www.ncbi.nlm.nih.gov/sra/SRP080980.

\section{SCFA data analysis}

Statistical analysis was performed using $\mathrm{R}$ software, version 3.0.1. Data are displayed as the mean \pm standard error (S.E.). The Kruskal-Wallis test was applied to analyze global differences among three groups. Tukey's method was used as a post-hoc test for multiple comparisons of means.

\section{Results}

\section{Nutrient content in the three feeds and growth of grass carp}

As expected, fresh hybrid giant napier contained the highest content of crude fiber $(23.96 \pm 1.68 \%$, dry matter), followed by formula feed $(9.70 \pm 0.46 \%$, dry matter $)$ and marinated broad beans $(1.98 \pm 0.89 \%$, dry matter). Fresh hybrid giant napier contained the lowest content of crude protein $(12.36 \pm 1.92 \%$, dry matter), followed by formula feed $(28.78 \pm 0.00 \%$, dry matter) and marinated broad beans $(31.78 \pm 1.86 \%$, dry matter) (Table 1).

Table 1. Nutrient contents in three feeds used to feed grass carp (\% dry matter). The superscripted lowercase letters indicate significant differences observed between different feeds. The same superscripted letters reflect cases where no significant difference was found, whereas different superscripted letters represent cases where significant differences were found $(p<0.05)$

\begin{tabular}{c|c|c|c|c|c|c}
\hline \multirow{2}{*}{ Nutrient component } & \multicolumn{2}{|c|}{ Hybrid giant napier (\%) } & \multicolumn{2}{|c|}{ Broad bean (\%) } & \multicolumn{2}{c}{ Formula feed (\%) } \\
\cline { 2 - 7 } & Mean & S. E. & Mean & S. E. & Mean & S. E. \\
\hline Crude fiber content & $23.96^{\mathrm{a}}$ & 1.68 & $1.98^{\mathrm{c}}$ & 0.89 & $9.70^{\mathrm{b}}$ & 0.46 \\
Crude ash content & $13.33^{\mathrm{a}}$ & 1.20 & $3.76^{\mathrm{c}}$ & 0.00 & $7.53^{\mathrm{b}}$ & 0.07 \\
Crude protein content & $12.36^{\mathrm{a}}$ & 1.92 & $31.78^{\mathrm{c}}$ & 1.86 & $28.78^{\mathrm{b}}$ & 0.00 \\
Crude fat content & $3.23^{\mathrm{b}}$ & 0.13 & $<1.11^{* \mathrm{a}}$ & NA & $5.42^{\mathrm{c}}$ & 0.26 \\
\hline
\end{tabular}

*The content of crude fat in the marinated broad beans was below the limit of detection

At the start of the experiment, the average weights of grass carp in groups fed hybrid giant napier, formula feed, and marinated broad bean were $501.5 \pm 20.17 \mathrm{~g}$, $501.33 \pm 15.00 \mathrm{~g}$, and $498.83 \pm 21.44 \mathrm{~g}$, respectively. No significant differences were observed. However, at the end of the two-month experiment, the average weights were $680.17 \pm 15.17 \mathrm{~g}, 918.00 \pm 46.67 \mathrm{~g}$, and $602.50 \pm 10.50 \mathrm{~g}$, respectively. The weight increases were $178.67 \pm 13.67 \mathrm{~g}, 416.67 \pm 53.33 \mathrm{~g}$, and $103.67 \pm 15.11 \mathrm{~g}$, which represented significant differences, in each case (Appendix 1).

\section{Concentrations of SCFAs in feeds and gut contents of grass carp fed different feeds}

The concentrations of acetate, propionate, and i-valerate in broad beans were the highest among the three feeds, whereas the absolute concentrations of all SCFAs in the 
hindguts of grass carp fed with formula feed were the highest $(1.95 \pm 1.06 \mathrm{mmol} / \mathrm{kg}$, $0.54 \pm 0.16 \mathrm{mmol} / \mathrm{kg}$, and $0.13 \pm 0.01 \mathrm{mmol} / \mathrm{kg}$ for acetate, propionate, and butyrate, respectively), followed by those from grass carp fed marinated broad beans and fresh hybrid giant napier (Table 2). Although the absolute concentrations were different, the three most dominant SCFAs in the guts of all of grass carp fed with different feeds were acetate, propionate, and butyrate. The ratios of their concentrations (approximately 14.3: 2.5: 1) were similar in all grass carp contents (Table 2). These results showed that the SCFA concentrations in the feeds and the metabolic activity of the hindgut microbiota markedly influenced SCFA concentrations in the hindgut of grass carp.

Table 2. Absolute concentrations of short-chain fatty acids (SCFAs) in the three feeds and in the hindguts of grass carp fed with the three feeds. HG, hindgut contents of grass carp fed with fresh hybrid giant napier (Pennisetum sinese Roxb); BG, hindgut contents of grass carp fed with marinated broad beans (Vicia faba); FG, hindgut contents of grass carp fed with formula feed; $H$, fresh hybrid giant napier; $B$, marinated broad beans; $F$, formula feed. The superscripted lowercase letters indicate significant differences observed between different feeds. The same superscripted letter shows instances where no significant difference was found, and different superscripted letters indicate cases where significant differences $(p<0.05)$ were found. Data are displayed as the mean \pm standard error (S.E.)

\begin{tabular}{c|c|c|c|c|c|c|c}
\hline & $\begin{array}{c}\text { Sample } \\
\text { size }\end{array}$ & $\begin{array}{c}\text { Acetate } \\
(\mathbf{m m o l} / \mathbf{k g})\end{array}$ & $\begin{array}{c}\text { Propionate } \\
(\mathbf{m m o l} / \mathbf{k g})\end{array}$ & $\begin{array}{c}\text { Butyrate } \\
(\mathbf{m m o l} / \mathbf{k g})\end{array}$ & $\begin{array}{c}\text { Iso-butyrate } \\
(\mathbf{m m o l} / \mathbf{k g})\end{array}$ & $\begin{array}{c}\text { Valerate } \\
(\mathbf{m m o l} / \mathbf{k g})\end{array}$ & $\begin{array}{c}\text { Iso-valerate } \\
(\mathbf{m m o l} / \mathbf{k g})\end{array}$ \\
\hline HG & 3 & $0.31 \pm 0.03$ & $0.02 \pm 0.00^{\mathrm{a}}$ & $0.01 \pm 0.00^{\mathrm{a}}$ & $0.01 \pm 0.00^{\mathrm{a}}$ & $0.00 \pm 0.00^{\mathrm{a}}$ & $0.00 \pm 0.00^{\mathrm{a}}$ \\
BG & 3 & $1.07 \pm 0.51$ & $0.14 \pm 0.03^{\mathrm{a}}$ & $0.04 \pm 0.02^{\mathrm{a}}$ & $0.01 \pm 0.00^{\mathrm{a}}$ & $0.00 \pm 0.00^{\mathrm{a}}$ & $0.01 \pm 0.00^{\mathrm{a}}$ \\
FG & 3 & $1.95 \pm 1.06$ & $0.54 \pm 0.16^{\mathrm{b}}$ & $0.13 \pm 0.01^{\mathrm{b}}$ & $0.03 \pm 0.00^{\mathrm{b}}$ & $0.02 \pm 0.00^{\mathrm{b}}$ & $0.03 \pm 0.00^{\mathrm{b}}$ \\
H & 3 & $0.14 \pm 0.01$ & $0.01 \pm 0.00$ & $0.01 \pm 0.00$ & $0.01 \pm 0.00$ & $0.00 \pm 0.00$ & $0.00 \pm 0.00$ \\
B & 3 & $1.82 \pm 1.15$ & $0.26 \pm 0.34$ & $0.05 \pm 0.06$ & $0.02 \pm 0.01$ & $0.01 \pm 0.00$ & $0.04 \pm 0.01$ \\
F & 3 & $1.05 \pm 0.04$ & $0.20 \pm 0.01$ & $0.08 \pm 0.00$ & $0.02 \pm 0.00$ & $0.01 \pm 0.00$ & $0.02 \pm 0.00$ \\
\hline
\end{tabular}

To measure the SCFA increment in the hindgut region of grass carp fed with different feeds, the ratios of SCFA concentrations in the hindgut of each group to those in the feed were calculated. In terms of the total SCFA concentration (i.e., the sum of the concentrations of acetate, propionate, butyrate, iso-butyrate, valerate, and iso-valerate), the ratio for HG was the highest (1.98), followed by those for FG (1.95) and BG (0.58). The crude fiber contents in different feeds positively associated with SCFA $\left(\mathrm{R}^{2}=0.890\right)$ and acetate $\left(\mathrm{R}^{2}=0.989\right)$ increments in grass carp, but negatively associated with propionate $\left(\mathrm{R}^{2}=0.895\right)$ and butyrate $\left(\mathrm{R}^{2}=0.837\right)$ increases $($ Fig. 1$)$. These findings implied that incremental changes of SCFAs, especially acetate in the hindguts of grass carp, were associated with the fiber contents of feeds.

\section{Gut microbiota composition of grass carp fed different feeds}

In this study, 451,160 high-quality spliced sequences from 9 samples were obtained. To eliminate the impediment of sequencing depths for each sample in determining the reliability, each sample was re-sampled at 29,918 sequences to assess their microbiotas. After re-sampling, 628 OTUs from 284 genera were detected using the criterion of $97 \%$ sequence similarity. An average of 190 OTUs (ranging from 93 
to 310) were detected in each sample (Appendix 2). The alpha diversity (Chao1 and Shannon indexes) of the gut microbiota was highest in the BG group, followed by the HG group, and lowest in the FG group (Appendix 2). The rarefaction curves of the OTUs showed that the sequence datasets could be used to represent the diversities and structures of each microbiota (Appendix 3).
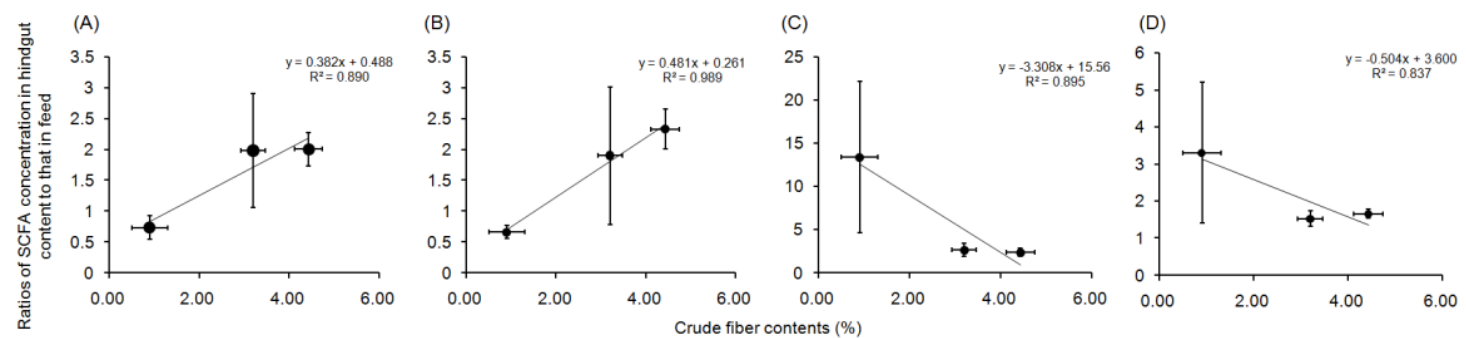

Figure 1. Ratios of SCFA concentrations in the hindguts of grass carp to those in different feeds. (A) Ratios of all SCFA concentrations (i.e. total concentrations of acetate, propionate, butyrate, iso-butyrate, valerate, and iso-valerate). (B) Ratios for acetate. (C) Ratios for propionate. (D) Ratios for butyrate

Except for a minority of sequences (ranging from $0.03 \%$ to $0.17 \%$ ) that could not be classified into any phylum, 19 phyla consisting of 1 Archaea phylum and 18 Bacteria phyla were found. Fusobacteria (40.92\%), Proteobacteria (26.40\%), Firmicutes (25.04\%), Bacteroidetes (5.61\%), and Cyanobacteria (1.46\%) were the dominant phyla in the gut microbiota of the grass carp (Fig. 2A). In this study, differences in the phylum compositions of the gut microbiota among the grass carp fed different diets were observed. The relative abundance of Bacteroidetes in the hindgut microbiota of the BG group was significantly higher than that found with the other diets, whereas the relative abundance of Fusobacteria was significantly lower (Fig. 2B). The relative abundance of Firmicutes in the hindgut microbiota of the FG group was significantly lower than that in the other groups (Fig. 2B). Moreover, the relative abundance of Proteobacteria in the BG group was significantly higher than that of the HG group (Fig. 2B). These results indicated that diet could fundamentally change the gut microbiota composition at the phylum level.

CA based on the OTUs and genus compositions of the samples showed a clear separation of the community composition among three treatment groups and revealed that diet significantly changed the hindgut microbiota of grass carp (Fig. $3 A$ and $B$ ). MANOVA also revealed distinct differences among the gut microbiota of grass carp fed with different feeds $(P<0.05)$.

Fifty-three dominant genera (relative abundances $>0.1 \%$ in at least one sample) was detected. They clustered into three different groups according to diet (Fig. 4A). The relative abundances of Cetobacterium in the FG and HG were obviously higher than those in the BG group. The relative abundances of Lactobacillus, Pediococcus, Bacillus, an unidentified Streptophyta genus, and an unidentified Staphylococcaceae genus in the HG group were obviously higher than those in the FG and BG groups. The relative abundances of $u 114$ of Fusobacteriaceae and an unidentified Betaproteobacteria genus in the FG group were obviously higher than those in the BG and HG groups, whereas the relative abundances of Bacteroides, Tolumonas, an unidentified Lachnospiraceae genus, and an unidentified Enterobacteriaceae genus 
were obviously higher in the BG group than those in the $\mathrm{HG}$ and $\mathrm{FG}$ groups (Fig. 4A). LEfSe results showed that the increased genus biomarkers in the HG group mostly concentrated in Lactobacillus, Pediococcus, Streptococcus, Enterococcus, and Leptotrichia; the increased genus biomarkers in the BG group mostly concentrated in Rhodobacter and Uliginosibacterium; and the increased genus biomarker in the FG group was mostly represented by Fusobacteria (Fig. 4B).

(A)

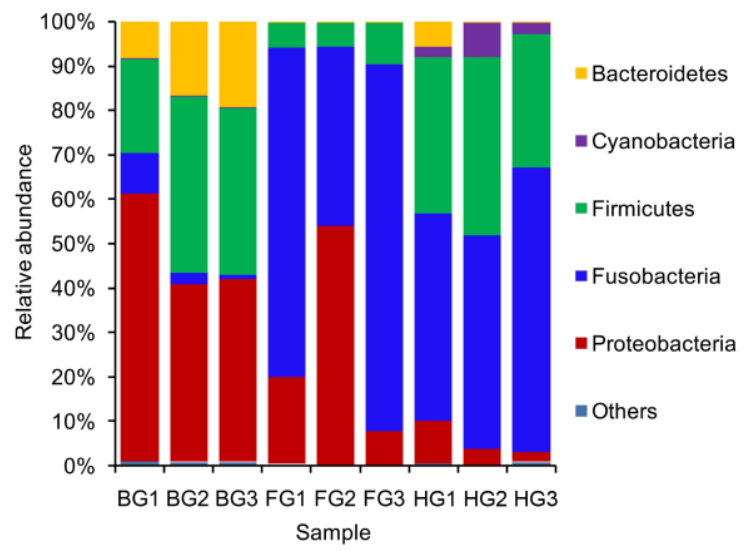

(B)

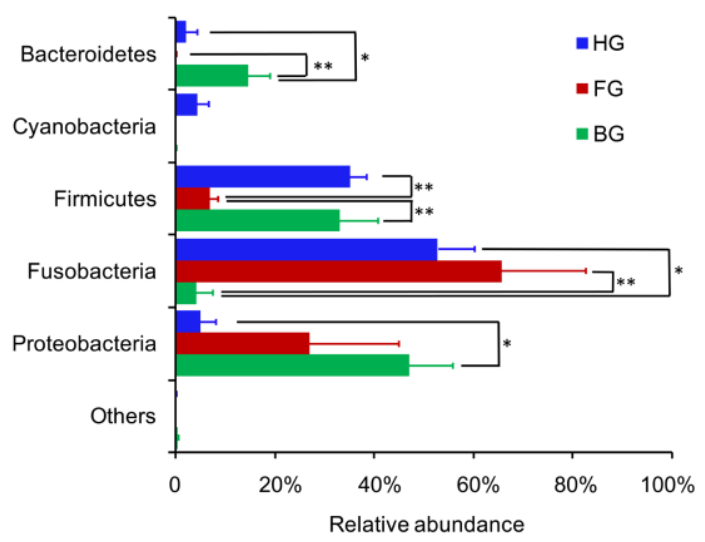

Figure 2. Phylum compositions of the gut microbiota in grass carp fed with different feeds. (A) The relative abundance of each bacterial phylum in each hindgut microbiota of grass carp fed with different feeds. (B) Significant differences in phylum abundances were found between the gut microbiota of grass carp fed with different feeds. FG, HG, and BG indicate the hindgut microbiota of grass carp fed with formula feed, fresh hybrid giant napier, and marinated broad beans, respectively. ${ }^{*} p<0.05, * * p<0.01$

(A)

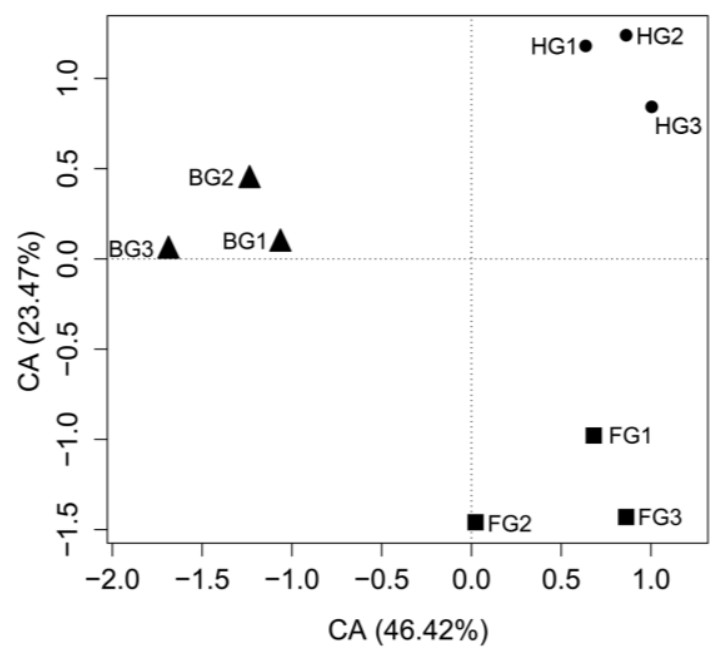

(B)

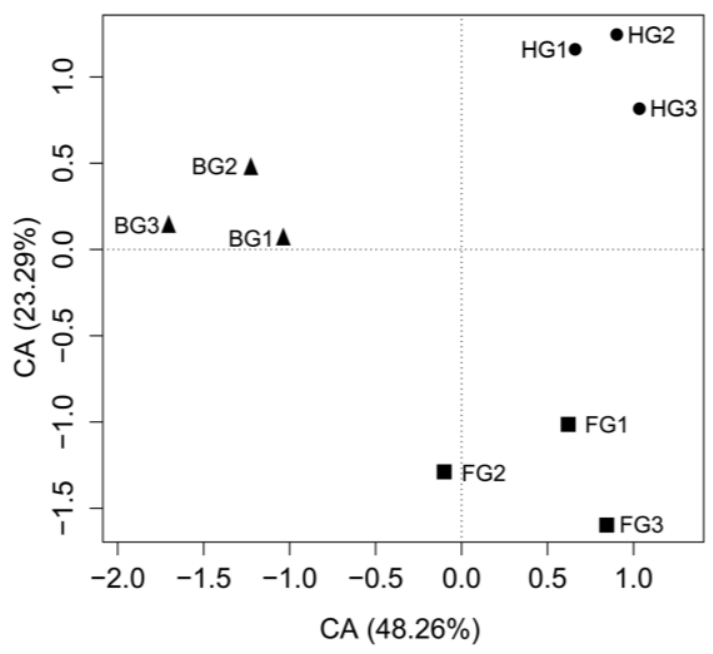

Figure 3. Correspondence analysis (CA) profiles of the gut microbiota genotypes in grass carp fed with different feeds. (A) and (B) show the CA profiles after analysis, based on the OTU and genus compositions, respectively. $F G, H G$, and $B G$ indicate the hindgut microbiota of grass carp fed with formula feed, fresh hybrid giant napier, and marinated broad beans, respectively 
(A)

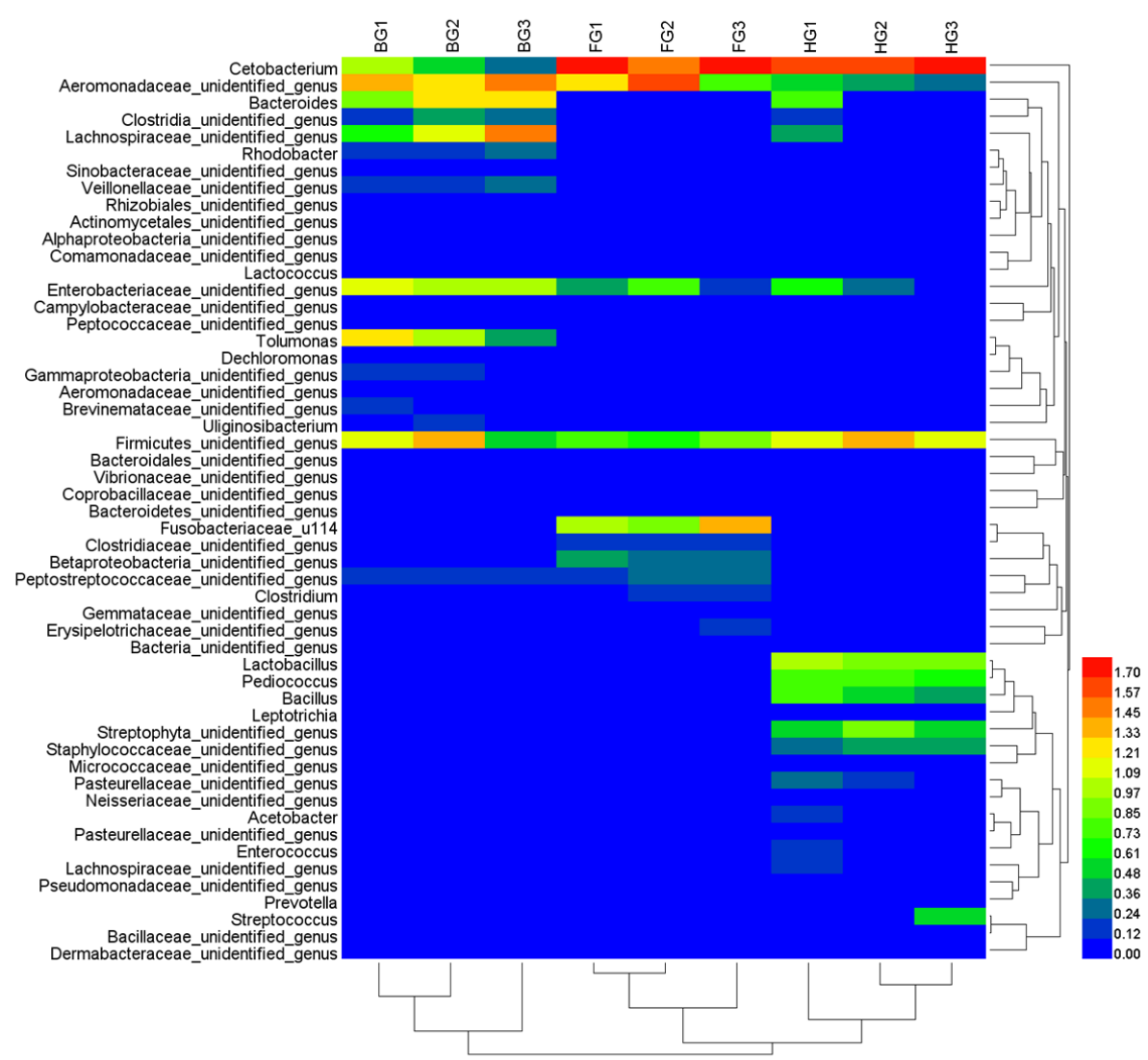

(B)

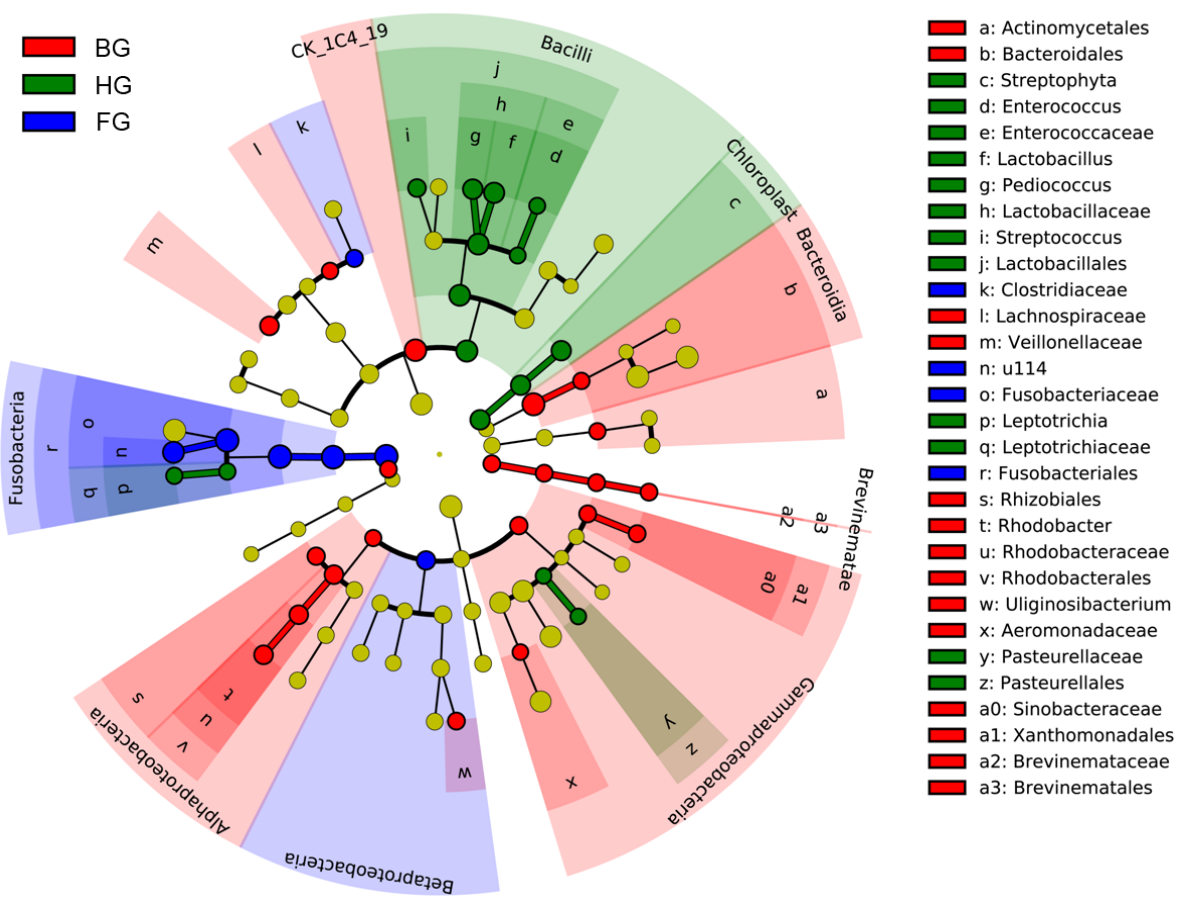

Figure 4. Heatmap $(A)$ and LEfSe (B) profiles showing the relative abundances of significantly different gut microbiota OTUs in grass carp fed with different feeds. FG, $H G$, and BG indicate the hindgut microbiota of grass carp fed with formula feed, fresh hybrid giant napier, and marinated broad beans, respectively 


\section{Discussion}

\section{Effects of diet on hindgut SCFA accumulation and the growth of grass carp}

Our results showed that changing the diet from natural food to formula feed significantly influenced the accumulation of SCFAs in the hindgut of grass carp (Table 2). Two dietary factors influenced SCFA accumulation in the hindgut of grass carp. Firstly, the diet directly supplied SCFAs to the hindgut of grass carp. Although SCFAs are thought to be mainly produced through carbohydrate fermentation by microorganisms, all three feeds had detectable SCFAs in this study (Table 2). Secondly, the amounts and species of SCFAs are significantly influenced by carbohydrate substrates (Hao et al., 2017a; Mountfort et al., 1993; Kihara and Sakata, 1997; Probert et al., 2004; Geraylou et al., 2014). Starch is seemingly more easily utilized to produce SCFAs through fermentation by gut microbiota in many fish (Kihara and Sakata, 1997; Van, 1994; Leenhouwers et al., 2007). This could explain the increased growth in grass carp fed formula feed compared with those fed with hybrid giant napier or broad beans, as formula feed contains more starch and higher luminal concentrations of SCFAs (Table 2).

\section{Proportional model and concentrations of SCFA metabolites in the grass carp hindgut}

In mammals and fishes, the SCFA metabolites produced during gut fermentation were mostly acetate, propionate, and butyrate (Clements et al., 1994; Hao et al., 2017b; Bergman, 1990; Smith et al., 1996; Cook and Sellin, 1998), and these metabolites were produced at different ratios. Acetate accumulation was most abundant ( $60 \%)$, followed by propionate $(\sim 25 \%)$ and then, to a much lesser degree, by butyrate $(\sim 15 \%)$ in human intestines (Fukuda et al., 2012). Although the ratios of acetate, propionate, and butyrate fluctuate among different species, the trends of these ratios (acetate $>$ propionate $\geq$ butyrate) were identical between mammals and fishes (Clements et al., 1994; Hao et al., 2017b; Bergman, 1990; Smith et al., 1996), with few exceptions in marine fishes (Kandel et al., 1994). Mountfort et al. (2002) reported the ratio of their concentrations in three species of marine fish as ranging from approximately 6.4: 3.2: 1 to 28.8: 9.8: 1, on average. In this study, the ratio of these concentrations was approximately 14.3: 2.5: 1 (Table 2). Therefore, changes in the acetate concentration primarily influenced the concentration of total SCFAs.

We found that the SCFA concentration in the grass carp hindgut ranged from 0.35 to $2.70 \mathrm{mmol} / \mathrm{kg}$, which is similar to findings reported by Hao et al. (2017a), but were lower than those reported by Paris et al. (Paris et al., 1977). Clements et al. (2014) compared the SCFA concentrations in the hindgut contents of 18 fishes. The SCFA concentrations ranged from 1.70 to $38.00 \mathrm{mM}$. In addition, the SCFA concentrations in hindgut contents of freshwater herbivore fish were commonly lower than in other fishes (Clements et al., 2014).

\section{Effect of dietary crude fiber contents on the SCFA increment of the grass carp hindgut microbiota}

Gut microbiota ferment dietary cellulose to SCFAs as energy sources and signaltransduction molecules in humans and mammals (Spiljar et al., 2017; Postler and Ghosh, 2017; Bindels et al., 2012; Hullar and Fu, 2014). Data from previous studies 
also indicated that the gut microbiota in herbivorous fish are capable of cellulose fermentation (Hao et al., 2017a, b; Ni et al., 2014a). Hao et al. (2017a) studied the influence of diets on the SCFA concentrations in the grass carp hindgut. Although they found that diets influenced SCFA concentrations in the hindgut, the influence of dietary SCFA concentrations was not demonstrated. The association between SCFA concentrations and the dietary cellulose contents was also not analyzed. However, the intestinal SCFA concentrations were clearly influenced by the dietary contents, as also shown in this study. Here, we used the ratios of intestinal SCFA concentrations to dietary SCFA concentrations to (i) exclude the influence of dietary SCFA concentrations on intestinal SCFA concentrations and to (ii) determine the SCFA increment. We found that the SCFA increment associated positively with the dietary cellulose contents in the three diets. The acetate increment, which represented the largest proportion of SCFAs, was highly positively associated with the dietary cellulose contents, but the increments of propionate and butyrate associated negatively with the dietary cellulose contents (Fig. 1). These results implied that acetate was probably produced in the hindgut of grass carp through cellulose fermentation, and the produced rates were faster than hindgut-absorption rates in the $\mathrm{HG}$ and FG, as the ratios were more than 1. However, most propionate and butyrate were probably not produced through cellulose fermentation, and their production and absorption in the hindgut were probably influenced by other undetected factors.

\section{Effect of dietary cellulose contents on the structure of grass carp hindgut microbiota}

In our study, we verified that the diet significantly changed the hindgut microbiota of grass carp, as reported previously (Ni et al., 2014b; Hao et al., 2017a). Changes in the hindgut microbiota of grass carp fed different diets also emerged at the phylum, genus, and OTU levels (Figs. 2-4). Similar to previous reports in grass carp and other fish (Hao et al., 2017b; Ni et al., 2014b; Miyake et al., 2015; Zhang et al., 2017), we found that Fusobacteria, Proteobacteria, Firmicutes, Bacteroidetes, and Cyanobacteria were the dominant phyla in the gut microbiota of the grass carp. However, their relative abundances acutely fluctuated between individuals fed different feeds or living in different habitats. Proteobacteria species dominate the intestines of many fish species, with differences found in the resident microbes (Zhang et al., 2017; Xia et al., 2014; Piazzon et al., 2017). Overgrowth of Proteobacteria was commonly associated with gut microbial dysbiosis and over-accumulation of energy in mammals. For instance, in Western-style diets, which are low in fiber, decreased beneficial Bacteroidetes and increased Proteobacteria levels are found, compared with those in a high-fiber diet (Geraylou et al., 2013). Dulski et al. (2018) speculated that Proteobacteria inhabiting the gut microbiota at an early stage of life are a necessary component of the pikeperch (Sander lucioperca) microbiome that may support proper nutrition of the fish. Fusobacteria species also dominated the intestines of grass carp in this study, as observed in other studies (Xia et al., 2014). However, the relative abundance of Fusobacteria species showed large fluctuations among different individuals under different conditions (Xia et al., 2014; Piazzon et al., 2017). Fusobacteria has been found to produce butyric acid as a major product of fermentation (Anand et al., 2016), and some species have been associated with diseases in mammals (Bennett and Eley, 1993).

$\mathrm{CA}$ of the $16 \mathrm{~S}$ rRNA gene-sequencing results also revealed that gut bacterial communities from grass carp fed different diets formed different clusters (Fig. 3A and B). The Pediococcus, Lactobacillus, Streptococcus, Enterococcus, and Leptotrichia 
genus biomarkers increased in the HG group (Fig. 4B). They were mostly represented by the Bacilli class, which contains many SCFA-producing bacteria, such as Pediococcus and Lactobacillus (Leblanc et al., 2017; Johansson et al., 1998; Li et al., 2016b, 2009; Dar et al., 2015).

Fermentation of cellulose by the gut microbiota is a major source of SCFA production (Leblanc et al., 2017; Kasubuchi et al., 2015; Flint et al., 2015). The grass carp is basically herbivorous (Ni et al., 2014a; Wu et al., 2012), and its cellulosedegrading capability is important for improving the utilization rate of plant polysaccharides and the production of SCFAs (Li et al., 2016a). In this study, most bacteria showing changes in abundance were related to SCFA production. For instance, the relative abundances of Cetobacterium in the HG and FG groups were obviously higher than that in the BG group. Tsuchiya et al. (2008) reported that the Cetobacterium abundance positively associated with acetic and propionic acid production through fermentation. The ratios of the SCFA concentrations in the HG and FG hindgut contents of grass carp to those in the feed were also obviously higher.

The ability of both lactobacilli and Pediococcus to produce SCFAs is well documented (Leblanc et al., 2017; Zhang et al., 2017). For instance, Geraylou et al. (2013) found that arabinoxylan-derived oligosaccharides could stimulate the growth of lactic acid bacteria and Clostridium sp. in the sturgeon gut and enhance the SCFA levels in the hindgut of sturgeon. Within $24 \mathrm{~h}$, supplementation of Lactobacillus salivarius JCM 1230 and Lactobacillus agilis JCM 1048 in a simulated chicken cecum significantly increased propionate and butyrate formation (Meimandipour et al., 2010). Moreover, L. acidophilus CRL 1014 was also reported to increase the SCFA concentrations in a simulated human microbial ecosystem (Sivieri et al., 2013). Recently, Lactobacillus rhamnosus GG was included in a study with a mix of probiotic strains and prebiotics, where it could metabolize these prebiotics, leading to SCFA production (Leblanc et al., 2017). In our study, the relative abundances of Lactobacillus in the HG group were obviously higher compared to the other groups (Fig. 4A), as was the SCFA-production capability (Fig. 1A). Bacterial strains of Pediococcus have been widely reported as SCFA-producing bacteria (Dineshkumar, and Renu, 2008; Taheri et al., 2015). For instance, Iehata et al. (2010) reported Pediococcus sp. Ab1 treatment could improve the gut environment of the abalone, Haliotis gigantea. In our study, the relative abundances of Pediococcus in the HG group were obviously higher those in the other groups (Fig. 4A). Bacterial strains of Bacillus and Bacteroides were also reported to cause cell lysis and to be capable of SCFA and branched-chain short fatty acid biosynthesis (Kaneda, 1963; Mayhew et al., 1975; Dreher et al., 1976; Tsuchido et al., 1985; Pogribna et al., 2010; Ray et al., 2012; Hong et al., 2017). For instance, Li et al. (2016a) isolated some cellulolytic Bacillus strains from the gut contents of grass carp. Ray et al. (2012) reported that many Bacillus sp. could produce cellulase. Bacilli is the primary producers of butyrate (Flint et al., 2015; Kaoutari et al., 2013; Levy et al., 2016). Our results showed that the elevated genera in the HG group were mostly represented by Bacilli (Fig. 4B). These results implied that cellulolytic bacteria would be enriched with high-cellulose substrates in the hindgut of grass carp. In addition, SCFAs were also indirectly produced from other intermediates that were produced by polysaccharide fermentation. For instance, lactate, which is produced by many members of the human gut microbiome, can serve as a substrate for the bacterial production of propionate (e.g., Coprococcus catus) and butyrate (e.g., Eubacterium hallii and Anaerostipes caccae) (Duncan et al., 2004; Reichardt et al., 2014). These findings imply 
that bacteria related to the SCFA concentration may not directly produce SCFAs, although they can increase the SCFA concentrations in the gut.

\section{Conclusions}

We conducted the first quantitative analysis of the association between SCFA accumulation and the dietary cellulose contents in this study. We found that the HG, which contained the highest dietary cellulose, exhibited the highest SCFA increase, even though the absolute concentration of SCFAs was higher in the FG, which contained more easily fermentable polysaccharides. Moreover, SCFA-producing bacteria, such as Lactobacillus, Pediococcus, and Bacillus, were significantly enhanced in the hindgut microbiota of the HG group. These results implied that the dietary cellulose content influenced the production of SCFAs in the grass carp hindgut by regulating the relative abundances of gut bacteria related to SCFA production. In addition, our results implied that adding appropriate proportion of cellulose or grass meal to grass carp feed could help to regulate the intestinal microbiota, and thereby increasing the content of SCFAs and increasing the growth and health of grass carp. However, the regulating mechanism of intestinal microbiota of grass carp to the productions of SCFAs needed to further study. These results would provide important reference for the design of grass carp feed formulation, and expand our understanding of the relationship between intestinal microbiota and grass carp metabolism.

Acknowledgements. We sincerely appreciate Yifei Wang and Wen Lou for their help in catching the experimental fish. We wish to thank Guangdong Meilikang BioScience, Ltd., for his help in analyzing the sequencing data and generating the pictures. This work was supported by the Central Public-interest Scientific Institution Basal Research Fund CAFS [2019XT0405, 2017HY-ZC0503] and the Modern Agro-industry Technology Research System [CARS-45-21].

\section{REFERENCES}

[1] Anand, S., Kaur, H., Mande, S. S. (2016): Comparative in silico analysis of butyrate production pathways in gut commensals and pathogens. - Frontiers in Microbiology 7: 1945.

[2] Anderson, M. J. (2001): A new method for non-parametric multivariate analysis of variance. - Austral Ecology 26: 32-46.

[3] Barczynska, R., Slizewska, K., Litwin, M., Szalecki, M., Kapusniak, J. (2016): Effects of dietary fiber preparations made from maize starch on the growth and activity of selected bacteria from the Firmicutes, Bacteroidetes, and Actinobacteria phyla in fecal samples from obese children. - Acta Biochimica Polonica 63: 261-266.

[4] Bennett, K. W., Eley, A. (1993): Fusobacteria: new taxonomy and related disease. Journal of Medical Microbiology 39: 246-254.

[5] Bergman, E. N. (1990): Energy contributions of volatile fatty acids from the gastrointestinal tract in various species. - Physiological Reviews 70: 567-590.

[6] Bindels, L. B., Porporato, P., Dewulf, E. M., Verrax, J., Neyrinck, A. M., Martin, J. C., et al. (2012): Gut microbiota-derived propionate reduces cancer cell proliferation in the liver. - British Journal of Cancer 107(8): 1337-1344.

[7] Bolnick, D. I., Snowberg, L. K., Hirsch, P. E., Lauber, C. L., Org, E., Parks, B., et al. (2015): Individual diet has sex-dependent effects on vertebrate gut microbiota. - Nature Communications 5: 4500. 
[8] Caporaso, J. G., Kuczynski, J., Stombaugh, J., Bittinger, K., Bushman, F. D., Costello, E. K., et al. (2010): QIIME allows analysis of high-throughput community sequencing data. - Nature Methods 7: 335-336.

[9] Claesson, M. J., Jeffery, I. B., Conde, S., Power, S. E., O’Connor, E. M., Cusack, S., et al. (2012): Gut microbiota composition correlates with diet and health in the elderly. Nature 488(7410): 178-184.

[10] Clements, K. D., Choat, J. H. (1995): Fermentation in tropical marine herbivorous fishes. - Physiological Zoology 68(3): 355-378.

[11] Clements, K. D., Choat, J. H. (1997): Comparison of herbivory in the closely-related marine fish genera Girella and Kyphosus. - Marine Biology 127: 579-586.

[12] Clements, K. D., Angert, E. R., Montgomery, W. L., Choat, J. H. (2014): Intestinal microbiota in fishes: what's known and what's not. - Molecular Ecology 23(8): 18911898.

[13] Clements, K. D., Gleeson, V. P., Slaytor, M. (1994): Short-chain fatty acid metabolism in temperate marine herbivorous fish. - Journal of Comparative Physiology - Part B 164: 372-377.

[14] Cohen, L. J., Esterhazy, D., Kim, S. H., Lemetre, C., Aguilar, R. R., Gordon, E. A., et al. (2017): Commensal bacteria make GPCR ligands that mimic human signalling molecules. - Nature 549(7670): 48-53.

[15] Cook, S. I., Sellin, J. H. (1998): Review article: short chain fatty acids in health and disease. - Alimentary Pharmacology and Therapeutics 12: 499-507.

[16] Da, S. B., Fdn, V., Jlp, M., Ferreira, G. S., Seiffert, W. Q. (2013): Salts of organic acids selection by multiple characteristics for marine shrimp nutrition. - Aquaculture 384(6): 104-110.

[17] Dar, M. A., Pawar, K. D., Jadhav, J. P., Pandit, R. S. (2015): Isolation of cellulolytic bacteria from the gastro-intestinal tract of Achatina fulica, (Gastropoda: Pulmonata) and their evaluation for cellulose biodegradation. - International Biodeterioration and Biodegradation 98: 73-80.

[18] Deng, W., Wang, Y., Liu, Z., Cheng, H., Xue, Y. (2014): HemI: a toolkit for illustrating heatmaps. - Plos One 9(11): e111988.

[19] Dineshkumar, N., Renu, A. (2008): Preparation of a probiotic fermented milk using a native isolate of Pediococcus pentosaceus MTCC 5151. - Research Journal of Biotechnology 3(3): 28-31.

[20] Dixon, P. (2003): VEGAN, a package of R functions for community ecology. - Journal of Vegetation Science 14(6): 927-930.

[21] Dreher, R., Poralla, K., König, W. A. (1976): Synthesis of omega-alicyclic fatty acids from cyclic precursors in Bacillus subtilis. - Journal of Bacteriology 127(3): 11361140.

[22] Dulski, T., Zakęś, Z., Ciesielski, S. (2018): Characterization of the gut microbiota in early life stages of pikeperch Sander lucioperca. - Journal of Fish Biology 92(1): 94104.

[23] Duncan, S. H., Louis, P., Flint, H. J. (2004): Lactate-utilizing bacteria, isolated from human feces, that produce butyrate as a major fermentation product. - Applied and Environmental Microbiology 70(10): 5810-5817.

[24] Edgar, R. C. (2013): UPASE: highly accurate OUT sequences from microbial amplicon reads. - Nature Methods 10(10): 996-998.

[25] Faith, J. J., Gordon, J. I. (2011): Predicting a human gut microbiota's response to diet in gnotobiotic mice. - Science 333(6038): 101-104.

[26] FAO (2014): The state of world fisheries and aquaculture 2014. Opportunities and challenges. - Food and Agriculture Organization of the United Nations, Rome.

[27] Flint, H. J., Duncan, S. H., Scott, K. P., Louis, P. (2015): Links between diet, gut microbiota composition and gut metabolism. - The Proceedings of the Nutrition Society 74(1): 13-22. 
[28] Fukuda, S., Toh, H., Hase, K., Oshima, K., Nakanishi, Y., Yoshimura, K., et al. (2012): Bifidobacteria can protect from enteropathogenic infection through production of acetate. - Nature 469(5): 543-547.

[29] Geraylou, Z., Rurangwa, E., Wiele, T. V. D., Courtin, C. M., Delcour, J. A., Buyse, J., Ollevie, F. (2014): Fermentation of Arabinoxylan-oligosaccharides, oligofructose and their monomeric sugars by hindgut bacteira from Siberian sturgeon and African catfish in batch culture in vitro. - Journal of Aquaculture Research and Development 5(3): 230.

[30] Geraylou, Z., Souffreau, C., Rurangwa, E., Maes, G. E., Spanier, K. I., Courtin, C. M., et al. (2013): Prebiotic effects of arabinoxylan oligosaccharides on juvenile Siberian sturgeon (Acipenser baerii) with emphasis on the modulation of the gut microbiota using 454 pyrosequencing. - FEMS Microbiology Ecology 86(2): 357-371.

[31] Goosen, N. J., Görgens, J. F., Wet, L. F. D., Chenia, H. (2011): Organic acids as potential growth promoters in the South African abalone Haliotis midae. - Aquaculture 321(3): 245-251.

[32] Hao, Y. T., Wu, S. G., Jakovlić, I., Zou, H., Li, W. X., Wang, G. T. (2017a): Impacts of diet on hindgut microbiota and short-chain fatty acids in grass carp (Ctenopharyngodon idellus). - Aquaculture Research 48(11): 5595-5605.

[33] Hao, Y. T., Wu, S. G., Xiong, F., Tran, N. T., Jakovlić, I., Zou, H., et al. (2017b): Succession and Fermentation Products of Grass Carp (Ctenopharyngodon idellus) Hindgut Microbiota in Response to an Extreme Dietary Shift. - Frontiers in Microbiology 8: 1585.

[34] Hong, C., Chen, Y., Li, L., Chen, S., Wei, X. (2017): Identification of a key gene involved in branched-chain short fatty acids formation in Natto by transcriptional analysis and enzymatic characterization in Bacillus subtilis. - Journal of Agricultural and Food Chemistry 65(8): 1592-1597.

[35] Hullar, M. A. J., Fu, B. C. (2014): Diet, the gut microbiome, and epigenetics. - Cancer Journal 20(3): 170-175.

[36] Iehata, S., Inagaki, T., Okunishi, S., Nakano, M., Tanaka, R., Maeda, H. (2010): Improved gut environment of abalone Haliotis gigantea through Pediococcus sp. Ab1 treatment. - Aquaculture 305(1): 59-65.

[37] Johansson, M. L., Nobaek, S., Berggren, A., Nyman, M., Björck, I., Ahrné, S., et al. (1998): Survival of Lactobacillus plantarum DSM 9843 (299v), and effect on the shortfatty acid content of faeces after ingestion of a rose-hip drink with fermented oats. International Journal of Food Microbiology 42(1-2): 29-38.

[38] Kandel, J. S., Horn, M. H., Van, A. W. (1994): Volatile fatty acids in the hindguts of herbivorous fishes from temperate and tropical marine waters. - Journal of Fish Biology 45: 527-529.

[39] Kaneda, T. (1963): Biosynthesis of branched chain fatty acids. - Journal of Biological Chemistry 238(4): 1222-1228.

[40] Kaoutari, A. E., Armougom, F., Gordon, J. I., Raoult, D., Henrissat, B. (2013): The abundance and variety of carbohydrate-active enzymes in the human gut microbiota. Nature Reviews Microbiology 11(7): 497-504.

[41] Kasubuchi, M., Hasegawa, S., Hiramatsu, T., Ichimura, A., Kimura, I. (2015): Dietary gut microbial metabolites, short-chain fatty acids, and host metabolic regulation. Nutrients 7(4): 2839-2849.

[42] Kihara, M., Sakata, T. (2002): Production of short-chain fatty acids and gas from various oligosaccharides by gut microbes of carp (Cyprinus carpio L.) in micro-scale batch culture. - Comparative Biochemistry and Physiology - Part A 132: 333-340.

[43] Kihara, M., Sakata, T. (1997): Fermentation of dietary carbohydrates to short-chain fatty acids by gut microbes and its influence on intestinal morphology of a detritivorous teleost tilapia (Oreochromis niloticus). - Comparative Biochemistry and Physiology Part A 118(4): 1201-1207. 
[44] Leblanc, J. G., Chain, F., Martín, R., Bermúdez-Humarán, L. G., Courau, S., Langella, P. (2017): Beneficial effects on host energy metabolism of short-chain fatty acids and vitamins produced by commensal and probiotic bacteria. - Microbial Cell Factories 16(1): 79 .

[45] Leenhouwers, J. I., Ortega, R. C., Jaj, V., Schrama, J. W. (2007): Digesta characteristics in relation to nutrient digestibility and mineral absorption in Nile tilapia (Oreochromis niloticus L.) fed cereal grains of increasing viscosity. - Aquaculture 273(4): 556-565.

[46] Levy, M., Thaiss, C. A., Elinav, E. (2016): Metabolites: messengers between the microbiota and the immune system. - Genes and Development 30(14): 1589-1597.

[47] Li, H., Wu, S., Wirth, S., Hao, Y., Wang, W., Zou, H., et al. (2016a): Diversity and activity of cellulolytic bacteria, isolated from the gut contents of grass carp (Ctenopharyngodon idellus) (Valenciennes) fed on Sudan grass (Sorghum sudanense) or artificial feedstuffs. - Aquaculture Research 47(1): 153-164.

[48] Li, J., Hou, J., Zhang, P., Liu, Y., Xia, R., Ma, X. (2016b): Comparative study of intestinal microbial community structure in different species of carp in aquaponics system. - South China Fisheries Science 12(6): $42-50$ (in Chinese).

[49] Li, W., Huan, X., Zhou, Y., Ma, Q., Chen, Y. (2009): Simultaneous cloning and expression of two cellulase genes from bacillus subtilis newly isolated from golden takin (budorcas taxicolor bedfordi). - Biochemical and Biophysical Research Communications 383(4): 397-400.

[50] Li, Z., Che, J., Xie, J., Wang, G., Yu, E., Xia, Y., et al. (2017): Microbial succession in biofilms growing on artificial substratum in subtropical freshwater aquaculture ponds. FEMS Microbiology Letters 364(4): fnx017.

[51] Li, Z., Yu, E., Wang, G., Yu, D., Zhang, K., Gong, W., Xie, J. (2018): Broad Bean (Vicia faba L.) Induces intestinal inflammation in grass Carp (Ctenopharyngodon idellus $\mathrm{C}$. et $\mathrm{V}$ ) by increasing relative abundances of intestinal gram-negative and flagellated bacteria. - Frontiers in Microbiology 9: 1913.

[52] Mayhew, J. W., Onderdonk, A. B., Gorbach, S. L. (1975): Effects of time and growth media on short-chain fatty acid production by Bacteroides fragilis. - Applied Microbiology 29(4): 472-475.

[53] Meimandipour, A., HairBejo, M., Shuhaimi, M., Azhar, K., Soleimani, A. F., Rasti, B., Yazid, A. M. (2010): Gastrointestinal tract morphological alteration by unpleasant physical treatment and modulating role of Lactobacillus in broilers. - British Poultry Science 51(1): 52-59.

[54] Miyake, S., Ngugi, D. K., Stingl, U. (2015): Diet strongly influences the gut microbiota of surgeonfishes. - Molecular Ecology 24(3): 656-672.

[55] Mountfort, D. O., Grant, W. D., Morgan, H., Rainey, F. A., Stackebrandt, E. (1993): Isolation and characterization of an obligately anaerobic, pectinolytic, member of the genus Eubacterium from mullet gut. - Archives of Microbiology 159(3): 289-295.

[56] Mountfort, D. O., Campbell, J., Clements, K. D. (2002): Hindgut fermentation in three species of marine herbivorous fish. - Applied and Environmental Microbiology 68(3): 1374-1380.

[57] Ni, J., Yan, Q., Yu, Y., Zhang, T. (2014a): Factors influencing the grass carp gut microbiome and its effect on metabolism. - FEMS Microbiology Ecology 87(3): 704714.

[58] Ni, J., Yan, Q., Yu, Y., Zhang, T. (2014b): Fish gut microecosystem: a model for detecting spatial pattern of microorganisms. - Chinese Journal of Oceanology and Limnology 32(1): 54-57.

[59] Paris, H., Murat, J. C., Castilla, C. (1977): Etude des acides grasvolatilsdans l'intestintroise speces de Poissons Teleosteens. - Comptes Rendus des Seances de la Societe de Biologieet de ses Filiales 171: 1297-1301. 
[60] Piazzon, M. C., Calduchginer, J. A., Fouz, B., Estensoro, I., Simómirabet, P., Puyalto, M., et al. (2017): Under control: how a dietary additive can restore the gut microbiome and proteomic profile, and improve disease resilience in a marine teleostean fish fed vegetable diets. - Microbiome 5(1): 164.

[61] Pogribna, M., Freeman, J. P., Paine, D., Boudreau, M. D. (2010): Effect of Aloe vera whole leaf extract on short chain fatty acids production by Bacteroides fragilis, Bifidobacterium infantis and Eubacterium limosum. - Letters in Applied Microbiology 46(5): 575-580.

[62] Postler, T. S., Ghosh, S. (2017): Understanding the holobiont: How microbial metabolites affect human health and shape the immune system. - Cell Metabolism 26(1): 110-130.

[63] Probert, H. M., Apajalahti, J. H. A., Rautonen, N., Stowell, J., Gibson, G. R. (2004): Polydextrose, lactitol, and fructo-oligosaccharide fermentation by colonic bacteria in a three-stage continuous culture system. - Applied and Environmental Microbiology 70(8): 4505-4511.

[64] R Core Team. (2014): R: A language and environment for statistical computing. - R Foundation for Statistical Computing, Vienna, Austria. http://www.r-project.org/.

[65] Ray, A. K., Ghosh, K., Ringø, E. (2012): Enzyme-producing bacteria isolated from fish gut: a review. - Aquaculture Nutrition 18(5): 465-492.

[66] Reichardt, N., Duncan, S. H., Young, P., Belenguer, A., Mcwilliam, L. C., Scott, K. P., et al. (2014): Phylogenetic distribution of three pathways for propionate production within the human gut microbiota. - The ISME Journal 8(6): 1323-1335.

[67] Ringø, E. (1992): Effects of dietary formate and acetate on growth and lipid digestibility in Arctic charr, Salvelinus alpinus (L.). - Fiskeridirektoratets Skrifter Serie Ernaering 5: 17-24.

[68] Safari, R., Hoseinifar, S. H., Kavandi, M. (2016): Modulation of antioxidant defense and immune response in zebra fish (Danio rerio) using dietary sodium propionate. Fish Physiology and Biochemistry 42(6): 1733-1739.

[69] Schwiertz, A., Taras, D., Schäfer, K., Beijer, S., Bos, N. A., Donus, C., Hardt, P. D. (2012): Microbiota and SCFA in lean and overweight healthy subjects. - Obesity 18(1): 190-195.

[70] Seeto, G. S., Veivers, P. C., Clements, K. D., Slaytor, M. (1996): Carbohydrate utilisation by microbial symbionts in the marine herbivorous fishes Odax cyanomelas and Crinodus lophodon. - Journal of Comparative Physiology - Part B 165: 571-579.

[71] Sivieri, K., Morales, M. L. V., Adorno, M. A. T., Sakamoto, I. K., Saad, S. M. I., Rossi, E. A. (2013): Lactobacillus acidophilus CRL 1014 improved "gut health" in the SHIME reactor. - BMC Gastroenterology 13(1): 100.

[72] Smith, T. B., Wahl, D. H., Mackie, R. I. (1996): Volatile fatty acids and anaerobic fermentation in temperate piscivorous and omnivorous freshwater fish. - Journal of Fish Biology 48(5): 829-841.

[73] Spiljar, M., Merkler, D., Trajkovski, M. (2017): The immune system bridges the gut microbiota with systemic energy homeostasis: focus on TLRs, mucosal barrier, and SCFAs. - Frontiers in Immunology 8: 1353.

[74] Stevens, C. E., Hume, I. D. (1998): Contributions of microbes in vertebrate gastrointestinal tract to production and conservation of nutrients. - Physiological Reviews 78(2): 393-427.

[75] Taheri, H. R., Moravej, H., Malakzadegan, A., Tabandeh, F., Zaghari, M., Shivazad, M., Adibmoradi, M. (2015): Efficacy of Pediococcusacidl actici-based probiotic on intestinal coliforms and villus height, serum cholesterol level and performance of broiler chickens. - African Journal of Biotechnology 9(44): 7564-7567.

[76] Titus, E., Ahearn, G. A. (1991): Transintestinal acetate transport in a herbivorous teleost: Anion exchange at the basolateral membrane. - Journal of Experimental Biology 156: 41-61. 
[77] Tsuchido, T., Hiraoka, T., Takano, M., Shibasaki, I. (1985): Involvement of autolysin in cellular lysis of Bacillus subtilis induced by short- and medium-chain fatty acids. Journal of Bacteriology 162(1): 42-46.

[78] Tsuchiya, C., Sakata, T., Sugita, H. (2008): Novel ecological niche of Cetobacterium somerae, an anaerobic bacterium in the intestinal tracts of freshwater fish. - Letters in Applied Microbiology 46(1): 43-48.

[79] Van, S. P. J. (1994): Nutritional Ecology of the Ruminant. 2nd Ed. - Cornell University Press, Ithaca.

[80] Wang, Q., Garrity, G. M., Tiedje, J. M., Cole, J. R. (2007): Naïve Bayesian classifier for rapid assignment of rRNA sequences into the new bacterial taxonomy. - Applied and Environmental Microbiology 73(16): 5261.

[81] Wang, Y., Lu, Y., Zhang, Y., Ning, Z., Li, Y., Zhao, Q., et al. (2015): Erratum: the draft genome of the grass carp (Ctenopharyngodono idellus) provides insights into its evolution and vegetarian adaptation. - Nature Genetics 47(8): 625-631.

[82] Wu, S., Wang, G., Angert, E. R., Wang, W., Li, W., Zou, H. (2012): Composition, diversity, and origin of the bacterial community in grass carp intestine. - Plos One 7(2): e30440.

[83] Xia, J. H., Lin, G., Fu, G. H., Wan, Z. Y., Lee, M., Wang, L., et al. (2014): The intestinal microbiome of fish under starvation. - BMC Genomics 15(1): 266.

[84] Yan, Q., Li, J., Yu, Y., Wang, J., He, Z., Van Nostrand, J. D., et al. (2016): Environmental filtering decreases with fish development for the assembly of gut microbiota. - Environmental Microbiology 18(12): 4739-4754.

[85] Zhang, Z., Li, D., Refaey, M. M., Xu, W. (2017): High spatial and temporal variations of microbial community along the Southern catfish gastrointestinal tract: insights into dynamic food digestion. - Frontiers in Microbiology 8: 1531.

\section{APPENDIX}

Appendix 1. Weight increments of grass carp feed two months of hybrid giant napier $(H G)$, formula feed $(F F)$, or marinated broad beans $(B B)$, respectively

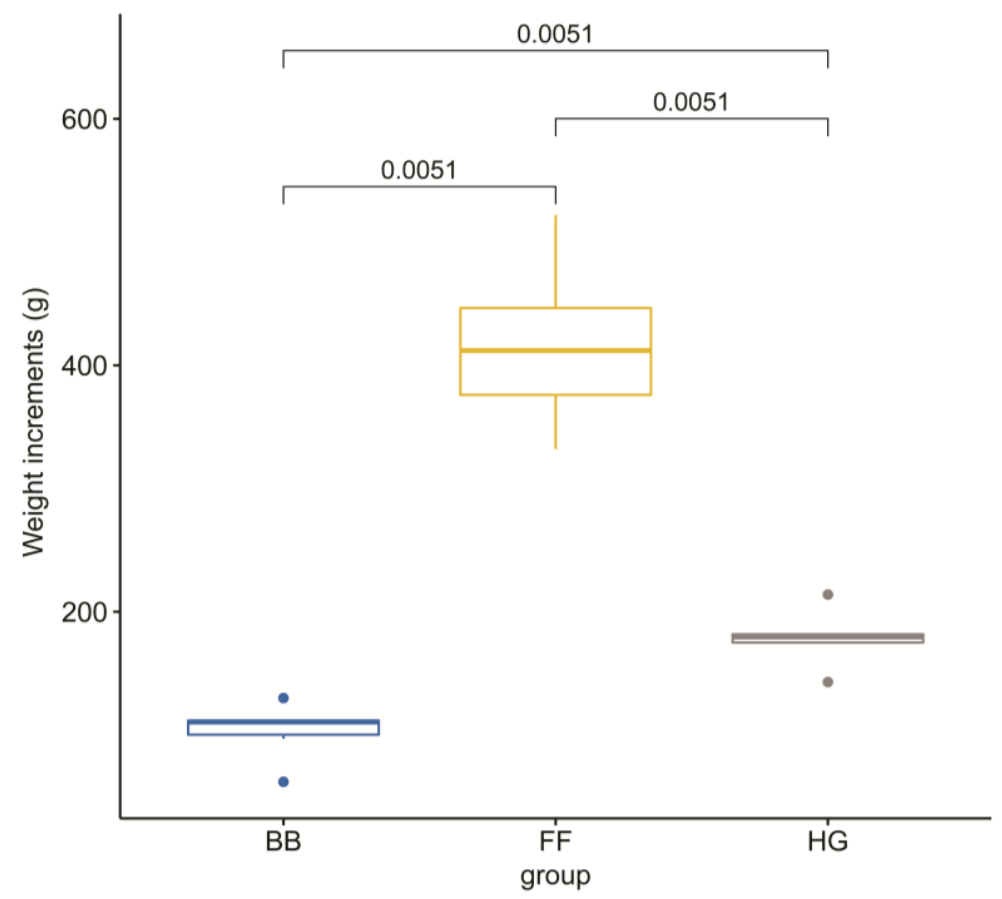


Appendix 2. Sequencing information of samples for microbiota analysis. $F G, H G$, and $B G$ indicate the hindgut microbiota of the grass carp fed formula feed, hybrid giant napier, and marinated broad beans, respectively

\begin{tabular}{c|c|c|c|c|c|c|c|c}
\hline $\begin{array}{c}\text { Sample } \\
\text { ID }\end{array}$ & $\begin{array}{c}\text { Raw } \\
\text { sequence }\end{array}$ & $\begin{array}{c}\text { Clean } \\
\text { sequence }\end{array}$ & $\begin{array}{c}\text { Effective } \\
\text { sequence }\end{array}$ & $\begin{array}{c}\text { Average } \\
\text { length (nt) }\end{array}$ & Q30 & $\begin{array}{c}\text { OUT } \\
\text { number }\end{array}$ & $\begin{array}{c}\text { Chao1 } \\
\text { index }\end{array}$ & $\begin{array}{c}\text { Shannon } \\
\text { index }\end{array}$ \\
\hline BG1 & 55,159 & 55,115 & 52,782 & 253 & 97.13 & 277 & 418.973 & 3.533 \\
BG2 & 54,108 & 54,075 & 50,859 & 253 & 97.13 & 291 & 350.381 & 3.57 \\
BG3 & 63,421 & 63,375 & 60,402 & 253 & 97 & 310 & 415 & 3.208 \\
HG1 & 62,086 & 60,662 & 57,635 & 253 & 96.98 & 209 & 246.561 & 3.366 \\
HG2 & 60,888 & 58,019 & 55,007 & 253 & 96.71 & 126 & 165 & 2.704 \\
HG3 & 59,094 & 57,268 & 55,248 & 252 & 96.88 & 198 & 265.097 & 2.408 \\
FG1 & 34,651 & 34,636 & 32,466 & 252 & 97.01 & 99 & 118.333 & 1.873 \\
FG2 & 43,641 & 43,617 & 39,371 & 253 & 97.04 & 93 & 118.87 & 2.071 \\
FG3 & 51,364 & 51,322 & 47,390 & 252 & 97.12 & 103 & 146.938 & 2.025 \\
\hline
\end{tabular}

Appendix 3. OTU rarefaction curves of the samples. $F G, H G$, and $B G$ indicate the hindgut microbiota of the grass carp fed formula feed, hybrid giant napier, and marinated broad beans, respectively

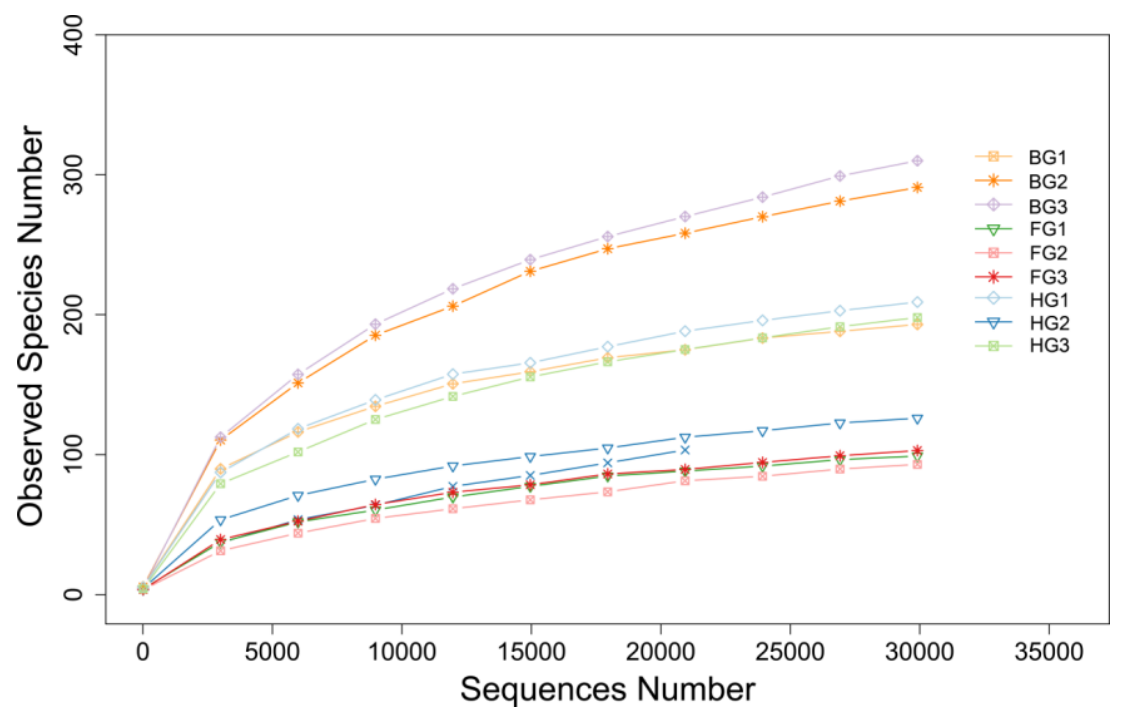

